\title{
On the Solidification of Rimmed Steel ${ }^{*}$
}

\author{
By Akira Masui, ${ }^{* *}$ Hideki Sato,** Masuta Ohkubo, ${ }^{* *}$ and \\ Shunkichi Miyoshi***
}

\section{Synopsis}

The rimming action during the solidification of rimmed steels is one of the most important factors which determine the quality of steel. The authors sectioned four 14-t bottom-poured rimmed steel ingots in order to study the phenomena which take place during rimming action.

A calculating method was proposed for the amount of $\mathrm{CO}$ gas evolution (rimming intensity), the degree of deoxidation by manganese, and the distribution of each solute element in the rim layer, based upon the teeming composition and the casting conditions. According to this method, the influences of oxygen, manganese, and carbon contents on the rimming intensity were discussed.

The mechanism of the primary blowhole formation was also studied; the thickness of solid skin and the length of primary blowhole were estimated from the teeming composition and the teeming conditions.

\section{Introduction}

Rimming action during solidification of rimmed steel is one of the most important factors which determine the quality of steels. The authors studied the solidification process of rimmed steel in order to adjust the intensity of rimming action for the better quality of rimmed steels.

The solidification process of rimmed steels has been studied by many authors including A. Hultgren. ${ }^{1)}$ However, most of these works with some exceptions ${ }^{2)-7)}$ were qualitative.

The present authors analyzed the present results in accordance with Nilles' method $^{6}$ ) of calculation. However, the calculation method of $\mathrm{P}$. Nilles resulted in some contradiction. Thus, subsequent analyses were carried out according to a mechanism devised by the authors.

Four bottom-poured rimmed steel ingots were used for analysis of cut sections to find the mechanism controlling the behaviors of elements under rimming action.

Furthermore, the influence of teeming composition $(\mathrm{C}, \mathrm{Mn}$, and $\mathrm{O})$ on the intensity of rimming action was studied from the analytical results. Examination was also made about the formation of primary blowholes in four test ingots.

\section{Method of Test}

For the purpose of investigating the solidification process of bottom-poured rimmed steel ingot, four test ingots were prepared and cut with various sections. A 14-t flat ingot mold $213 \mathrm{~cm}$ high was used.

Teeming time and the teeming composition are shown in Table 1 . The teeming rate was calculated from the equation based on experimental results and the rate was a square function of time,

$$
(d h / d t)=16.5-B t^{2}(\mathrm{~cm} / \mathrm{min})
$$

where $B$ is a coefficient that depends on the duration of the teeming time. The equation was used for subsequent calculations.

Since it was found for ingot No. 3 that $[\mathrm{C}]_{L},[\mathrm{Mn}]_{L}$, $[\mathrm{O}]_{L},[\mathrm{~S}]_{L}$, or $[\mathrm{P}]_{L}$ did not change significantly with the progress of rimming action, the composition of the liquid phase was assumed to be the same as teeming composition for all cases. The observed steady bulk composition could be attributed to the large ingot size which presumably reduced the influence of concentration built up from the solidification interface.

Prepared ingot pieces were subjected to macroscopic test and sulfur print to identify the rim layer, and were divided into three parts, i.e. top, middle, and bottom. Samples were then taken from bottom $(37.5 \mathrm{~cm}$ from the bottom), middle $(82.5 \mathrm{~cm})$, and top $(127.5 \mathrm{~cm})$ portions at every $1 \mathrm{~cm}$ from the ingot surface and were analyzed for each element. In an attempt to establish an equation to express solidifying rate, Lightfoot's equation $(D=A \sqrt{t})$ was used and the constant, $A$, was determined for each test ingot from the thickness of the rim layer and the rimming time (see Table 1).

\section{Various Phenomena Occurring in Rimming Action}

As molten steel containing solute atoms, e.g. S, P, $\mathrm{Mn}, \mathrm{C}, \mathrm{O}$, solidifies, excess solute atoms are rejected ahead of the advancing solid-liquid interface due to

Table 1. Casting conditions of ingots

\begin{tabular}{|c|c|c|c|c|c|c|}
\hline \multirow{2}{*}{$\begin{array}{l}\text { Ingot } \\
\text { No. }\end{array}$} & \multirow{2}{*}{$\begin{array}{l}\text { Teeming time } \\
\qquad(\min )\end{array}$} & \multirow{2}{*}{$\underset{(\min )}{\text { Rimming time }}$} & \multirow{2}{*}{$\begin{array}{c}A(\mathrm{~cm} / \sqrt{\mathrm{min}}) \\
(x=A \sqrt{t})\end{array}$} & \multicolumn{3}{|c|}{ Content at teeming } \\
\hline & & & & $\mathrm{C}(\%)$ & $\operatorname{Mn}(\%)$ & $\mathrm{O}(\%)$ \\
\hline 1 & 14.5 & 17.5 & 2.10 & 0.15 & 0.20 & 0.025 \\
\hline 2 & 14.9 & 21.4 & 2.58 & 0.09 & 0.25 & 0.030 \\
\hline 3 & 15.9 & 23.7 & 2.51 & 0.06 & 0.23 & 0.046 \\
\hline 4 & 14.5 & 19.4 & 2.85 & 0.06 & 0.29 & 0.044 \\
\hline
\end{tabular}

* $\quad$ Presented at the 73rd ISIJ Meeting, April, 1967 in Tokyo. Manuscript received December 7, 1967.

** Technical Research Institute, Nippon Kokan K.K., Minamiwatarida-cho, Kawasaki 210.

*** Keihin Works, Nippon Kokan K. K., Mizue-cho, Kawasaki 210. 
lower solubility of such atoms in solid iron. The transport of the solute atoms thus rejected are limited by diffusion rate in the liquid and in front of solidifying interface a "boundary layer" is formed. The steady state distribution of the solute atoms in the boundary layer was given by Burton ${ }^{8)}$ as:

$$
D_{i}\left(d^{2} C_{i} / d x^{2}\right)+\left(d C_{i} / d x\right)=0 .
$$

where, $x$ : distance from solid-liquid interface $(\mathrm{cm})$

$D_{i}$ : diffusion constant of element $i$ in the liquid $\left(\mathrm{cm}^{2} / \mathrm{sec}\right)$

$C_{i}$ : concentration of element $i$ at $x(\%)$

$f$ : solidifying rate (rate of movement of interface) $(\mathrm{cm} / \mathrm{sec})$.

By introducing the constants $A_{i}$ and $B_{i}$ determined by the boundary conditions, the solution of Eq. (1) can be expressed as

$$
C_{i}=A_{i}+B_{i} \exp \left(-f x / D_{i}\right)
$$

J. A. Burton et al. ${ }^{8)}$ confirmed that the excess solute atoms migrate only by diffusion up to a distance $\delta$ from the solidifying front and that the concentration beyond this distance became uniform through mixing. The concentration distribution is shown in Fig. 1.

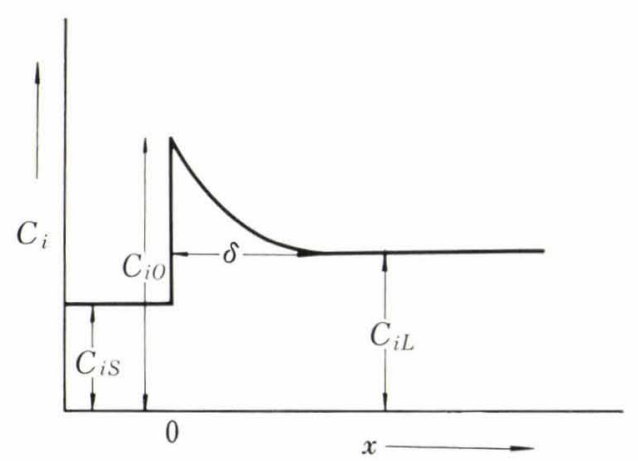

Fig. 1. Enrichment of solute atoms in front of a solidifying interface

Since $C_{i}=C_{i L}$ at $x=\delta$, the concentration at solidifying interface, $C_{i o}$, is given as

$$
C_{i o}=C_{i L}+B_{i}\left\{1-\exp \left(-f \delta / D_{i}\right)\right\} .
$$

where $B_{i}$ is a constant that depends on the boundary conditions at the solidifying interface with respect to element $i$. However, it is aiso necessary to táke into account of reactions occurring at the interface, if any, and therefore subsequent analyses were carried out separately for the both cases with or without such reactions.

\section{Elements without Reaction at Interface}

Since the solute concentration of the liquid at the solid-liquid interface $\left(C_{i 0}\right)$ is considered to reach equilibrium with that in the solid $\left(C_{i S}\right)$, the equilibrium partition ratios can be used at the interface:

$$
C_{i S}=K_{i} C_{i 0}
$$

where $K_{i}$ is the distribution coefficient.

The boundary conditions at the solidifying surface are given through material balance as

$$
D_{i}\left(d C_{i} / d x\right)_{x=0}+\left(1-K_{i}\right) f C_{i 0}=0 .
$$

From Eqs. (2), (3), (4), and (5), the concentration at solidifying interface becomes

$$
C_{i O}=C_{i L} /\left\{K_{i}+\left(1-K_{i}\right) \exp \left(-f \delta / D_{i}\right)\right\} \ldots
$$

For the elements that do not react at the interface, $\delta$ at a given moment can be calculated from the known concentrations of the solutes in the solid and in the bulk liquid by employing Eq. (6). Values in various publications ${ }^{9)-13)}$ of the distribution coefficient and the diffusion constant, listed in the following table, were used for numerical calculations.

\begin{tabular}{c|ccccc} 
& $\mathrm{C}$ & $\mathrm{Mn}$ & \multicolumn{1}{c}{$\mathrm{S}$} & $\mathrm{P}$ & $\mathrm{O}$ \\
\hline$K$ & 0.20 & 0.84 & 0.05 & 0.18 & 0.02 \\
$D\left(\times 10^{-5}\right)$ & 7.0 & 3.8 & 5.0 & 7.76 & 3.0
\end{tabular}

Comparison of the values of $\delta$ calculated with respect to $\mathrm{S}$ and $\mathrm{P}$, respectively, for the steel ingots listed in Table 1 showed the same value for the both cases as illustrated in Fig. 2. Furthermore, the relation between the calculated $\delta$ and the solidifying rate $f$ (Fig. 3) indicated that $\delta$ is determined only by $f$. It is generally believed that $\delta$ is controlled by the intensity of agitation related with rimming action. However, as Fig. 3 shows, the $\delta$ values distribute around the same straight line dependent on the solidification rate $f$ for both No. 3 ingot, (marked $\mathrm{O}$ ) with the most active rimming action and the most calculated $\mathrm{CO}$ production, and No. 1 ingot, (marked $x$ ) with the weakest rimming action. It is considered from this fact that $\delta$ is controlled exclusively by $f$ under the presently employed test conditions (teeming rate, temperature, casting procedure, mold shape, range of composition, rimming intensity, etc.). The sudden increase in $\delta$ for $f \leqslant 0.004$ is considered due to the drastic decrease of $\mathrm{CO}$ gas evolution by capping. In other words, $\delta$ may be a function of rimming action when rimming action is reduced to this degree. Consequently, for cases where the capping time is different, the increase of $\delta$ would start at a different time, and Fig. 3 will no longer hold without modification.

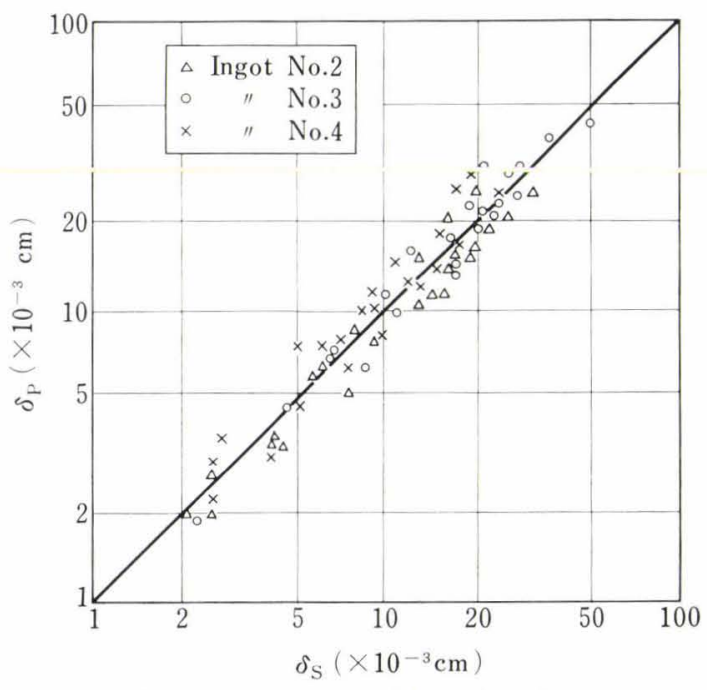

Fig. 2. Thickness of boundary layer 


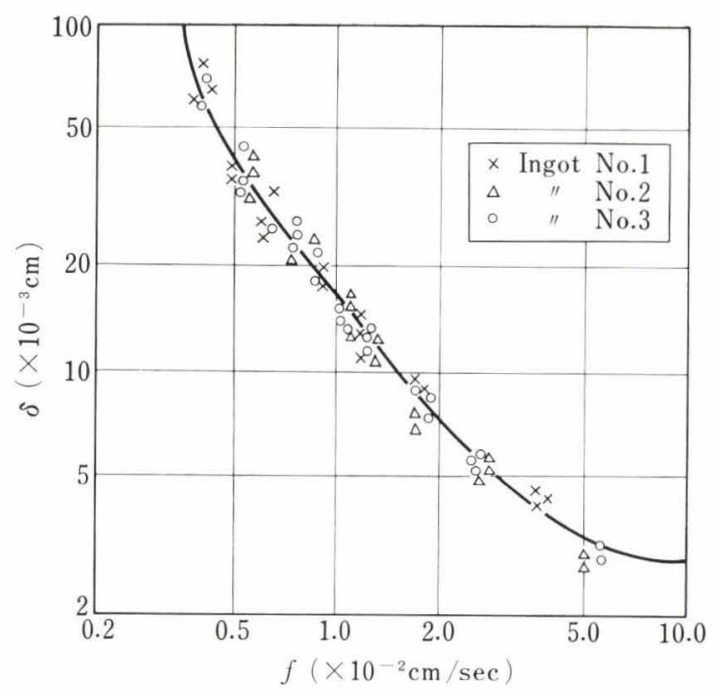

Fig. 3. Relation between solidifying rate $(f)$ and thickness $(\delta)$ of boundary layer

The relationship in Fig. 3 can be shown by the following equation:

$$
\delta=\left(5 \times 10^{-5} / f^{1.247}\right)+2.16 \times 10^{-2} f+\left(10^{-20} / f^{7.66}\right) \ldots
$$

From the above discussion, it is now clear that the thickness of the diffusion layer $(\delta)$ is a function only of the solidifying rate $(f)$. Therefore the concentration distribution of solute elements in the rim layer without any reaction, (i.e. $\mathrm{S}$ and $\mathrm{P}$ ) can be calculated through Eqs. (4), (6), and (7), where only necessary experimental value is the composition of the melt to be cast.

In Fig. 4, the calculated curves are compared with the observed values (plots) of the concentration distribution of $\mathrm{S}$ and $\mathrm{P}$ in the rim layer for ingots Nos. 3 and 2. Rimming action was most active for ingot No. 3 and relatively weak for ingot No. 2. The ratios of concentration in solid to that in liquid, i.e. $\mathrm{S}_{S} / \mathrm{S}_{L}$ and $\mathrm{P}_{S} / \mathrm{P}_{L}$, were taken as the ordinate to plot values for both ingots simultaneously.

Three plots for one value of $x$ indicate three analytical values for bottom, middle, and top portion of a ingot, respectively. The values for the top portion were always lower than those for others, presumably as a result of different cleaning effect of rimming action

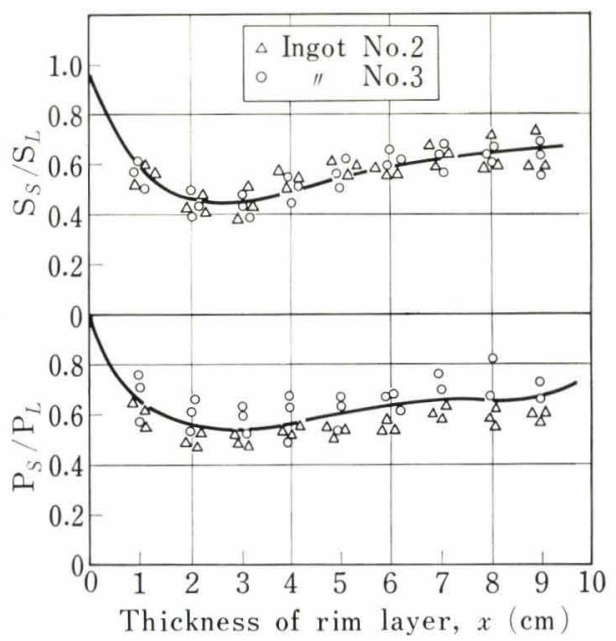

Fig. 4. Concentration distribution of $\mathrm{S}$ and $\mathrm{P}$ in rim layer depending on the position. The difference, however, was regarded in the present work as negligibly small.

\section{Elements with Reaction at Interface}

Various suggestions had been made about the kind of gas causing rimming action during solidification of rimmed steel, ${ }^{\prime \prime}$ but the analysis of the collected gas in the course of rimming action indicated that major portion of it consisted of $\mathrm{CO} .{ }^{24}$ ) On the other hand, the analysis of scum formed during rimming suggested the possibility of deoxidation by $\mathrm{Mn} .{ }^{5), 24), 25)}$ It is therefore necessary to consider reactions of $\mathrm{C}, \mathrm{O}$, and $\mathrm{Mn}$. Matsuno et al. ${ }^{7)}$ recently claimed that $\mathrm{C}-\mathrm{O}$ reaction and $\mathrm{Mn}-\mathrm{O}$ reaction took place at different locations. But the opinion of the present authors is that these reactions simultaneously proceed at the solidification front where $\mathrm{C}, \mathrm{Mn}$, and $\mathrm{O}$ reach their highest concentrations; much active $\mathrm{CO}$ formation reaction may bring the oxygen concentration at solidification front lower than the bulk concentration, but, even in this case, rimming action does not occur in the bulk because the nucleation reaction is more favorable at the solidification front.

If it is assumed that the solution of Eq. (1), and hence that of Eq. (2) are valid also in this case in spite of the presence of reactions, and that Burton's assumption also holds, Eq. (3) can be applied at the solidifying interface where reactions of solute atoms take place. The value of $\delta$ employed in Eq. (3) can be calculated from Eq. (7). Moreover, if an equilibrium is assumed to exist at the solid-liquid interface, Eq. (4) is also applicable. The boundary conditions at $x=0$, given as Eq. (5) for the previous case where no reaction takes place, now become as Eqs. (8), (9), and (10) for O, Mn, and C, respectively.

$$
\begin{aligned}
& D_{o}(d[\mathrm{O}] / d x)_{x=0}+\left(1-K_{\mathrm{O}}\right) f[\mathrm{O}]_{o}-f[\mathrm{O}]_{\mathrm{CO}} \\
& -f[\mathrm{O}]_{\mathrm{Mn}}=0 \\
& D_{\mathrm{Mn}}(d[\mathrm{Mn}] / d x)_{x=0}+\left(1-K_{\mathrm{Mn}}\right) f[\mathrm{Mn}]_{o} \\
& -\alpha f[\mathrm{O}]_{\mathrm{Mn}}=0 \text {. } \\
& D_{\mathrm{C}}(d[\mathrm{C}] / d x)_{x=0}+\left(1-K_{\mathrm{C}}\right) f[\mathrm{C}]_{o} \\
& -\beta f[\mathrm{O}]_{\mathrm{CO}}=0
\end{aligned}
$$

where, $D_{O}, D_{\mathrm{Mn}}, D_{\mathrm{C}}$ : diffusion constant of $\mathrm{O}, \mathrm{Mn}$, and $\mathrm{C}$ $\left(\mathrm{cm}^{2} / \mathrm{sec}\right)$

$[\mathrm{O}]_{O},[\mathrm{Mn}]_{O},[\mathrm{G}]_{O}: \mathrm{O}, \mathrm{Mn}$, and $\mathrm{C}$ concestrations at solidifying interface $(\%)$

$[\mathrm{O}]_{\mathrm{CO}}$ : concentration of oxygen consumed as $\mathrm{CO}(\%)$

$[\mathrm{O}]_{\mathrm{Mn}}$ : concentration of oxygen consumed as $\mathrm{MnO}$ and $\mathrm{FeO}$ in $\mathrm{Mn}$ deoxidation (\%)

$\alpha$ : ratio of oxygen consumed as $\mathrm{MnO}$ and $\mathrm{FeO}$ to $\mathrm{Mn}$ consumed as $\mathrm{MnO}$

$\beta: \quad 12 / 16$.

Unlike the cases where reactions are not involved, three variables, i.e. $[\mathrm{O}]_{\mathrm{CO}},[\mathrm{O}]_{\mathrm{Mn}}$, and $\alpha$ are now introduced: in the case where reaction of $\mathrm{Mn}$ is concerned, three unknown variables $[\mathrm{O}]_{\mathrm{CO}},[\mathrm{O}]_{\mathrm{Mn}}$, and $\alpha$ enter the calculation, and in the case where $\mathrm{Mn}$ does not react, there is only one unknown variable, $[\mathrm{O}]_{\mathrm{co}}$. Therefore, in order to solve Eqs. (8), (9), and (10), three additional relations are required for the former case, one more for the latter case. 
It may be considered that an equilibrium exists between $\mathrm{Mn}$ and $\mathrm{O}$ when reaction of $\mathrm{Mn}$ takes place. Also judging from the Mn concentration in ordinary rimmed steel, this equilibrium is considered to be also in equilibrium with solid $\mathrm{MnO}-\mathrm{FeO} .{ }^{26}$ ) These equilibria can be formulated as follows :

$$
\begin{aligned}
& \mathrm{FeO}(l)=\mathrm{Fe}(l)+\underline{\mathrm{O}} \\
& \Delta G^{\circ}=28930-12.51 \mathrm{~T} \\
& \mathrm{FeO}(l)+\mathrm{Mn}=\mathrm{MnO}(l)+\mathrm{Fe}(l) \\
& \Delta G^{\circ}=-29480+13.50 T \\
& \mathrm{FeO}(S)=\mathrm{FeO}(l) \\
& \Delta G^{\circ}=8000-4.83 T \\
& \operatorname{MnO}(S)=\operatorname{MnO}(l) \\
& \Delta G^{\circ}=10500-5.197 \\
& \log L_{O(S)}=-8072.1 / T+3.790^{14)} \\
& \log K_{\mathrm{Mn}(S)}=6990 / T-3.03^{14)} \\
& {[\mathrm{O}]_{o}=L_{o} /\left(K_{\mathrm{Mn}(S)}[\mathrm{Mn}]_{o}+1\right)} \\
& \alpha=(54.93 / 70.93)(\mathrm{MnO}) /\{(16 / 70.93) \\
& (\mathrm{MnO})+(16 / 71.85)(1-(\mathrm{MnO}))\} \\
& K_{\mathrm{Mn}(S)}=\mathcal{N}_{\mathrm{MnO}} / \mathcal{N}_{\mathrm{FeO}} \cdot[\mathrm{Mn}]_{o} \\
& \mathcal{N}_{\mathrm{FeO}}+\mathcal{N}_{\mathrm{MnO}}=1
\end{aligned}
$$

Thus, for the case where Mn takes part in reaction, equilibrium relationships of $\mathrm{Mn}$ give two equations (Eqs. (11) and (12)), which can be used to solve Eqs. (8) to (10). When Mn does not react, these two equations do not hold: in this case, $\alpha$ and $[\mathrm{O}]_{\mathrm{Mn}}$ are eliminated from Eqs. (8) and (9) because $[\mathrm{O}]_{\mathrm{Mn}}=0$.

The formation of $\mathrm{CO}$ at the solid-liquid interface seems to appear at certain locations and the C-O reaction may not occur uniformly at all sites. Macroscopic treatment, instead of microscopic one which is too complicated to accomplish, shows that so far as the average concentrations are concerned, the product of $[\mathrm{C}]_{o}$ and $[\mathrm{O}]_{o}$ in front of the solid-liquid interface is above equilibrium value. Thus, the melt is supersaturated with respect to carbon and oxygen.

Using the analytical data for the experimental ingots, the value of $[\mathrm{C}]_{o}$ and $[\mathrm{O}]_{o}$ were calculated according to the above equations, and the degree of supersaturation at the solidifying interface was calculated according to the following equations:

$$
\begin{gathered}
\qquad S P=K_{1}[\mathrm{C}]_{o}[\mathrm{O}]_{o}\left(K_{2}[\mathrm{O}]_{o}+1\right) / P \ldots \ldots \ldots . .(1 \\
\log K_{1}\left(=\log P_{\mathrm{CO}} / a_{\mathrm{C}} \cdot a_{\mathrm{O}}\right)=1160 / T-2.003^{15)} \\
\log K_{2}\left(=\log P_{\mathrm{CO}} / P_{\mathrm{CO}} \cdot a_{\mathrm{O}}\right)=8718 / T-4.762^{15)} \\
\text { where, } P: \quad \text { static pressure calculated from the teeming rate. }
\end{gathered}
$$

The degree of supersaturation represents the feasibility of $\mathrm{C}-\mathrm{O}$ reaction, and is considered to be controlled especially by the structure of growing crystals at the solidifying interface. This structure is affected by many factors, among which the most important would be the solidifying rate. Consequently, the next step was to study the relationship between the degree of supersaturation $(S P)$ and the solidifying rate. Results are shown in Fig. 5.

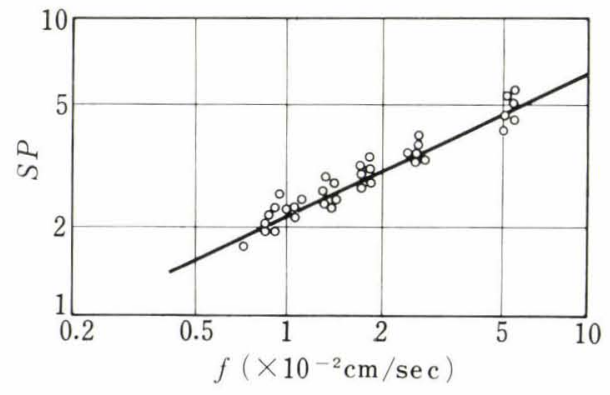

Fig. 5. Relation between solidifying rate $(f)$ and degree of supersaturation $(S P)$

From this figure, a relationship expressed by the following equation was obtained for the present test conditions.

$$
S P=17.2 f^{0.437}
$$

Combining Eq. (14) with equilibrium equations, the boundary condition formulated as Eqs. (8), (9), and (10) can be solved. Also for the case where Mn does not react, these equations can be solved by using Eq. (14) and $[\mathrm{O}]_{\mathrm{Mn}}=0$.

It is thus possible, from the teeming composition and the teeming rate, to calculate the concentration distribution in rim layer, the amount of $\mathrm{CO}$ gas evolution $\left([\mathrm{O}]_{\mathrm{co}}\right)$ and its rate $\left(f[\mathrm{O}]_{\mathrm{co}}\right)$, and the amount of deoxidation by $\mathrm{Mn}\left([\mathrm{O}]_{\mathrm{Mn}}\right)$ and its rate $\left(f[\mathrm{O}]_{\mathrm{Mn}}\right)$.

In order to demonstrate the validity of the conclusion, the concentration distribution of carbon in rim layer of the experimental ingots was compared with the observed distribution. The result is shown in Fig. 6. This figure covers values for ingots Nos. 1, 2, and 3 having different carbon content. Curves I, II, and III are the calculated distribution corresponding to the sections at the bottom, middle, and top, respectively. The different amount of $\mathrm{CO}$ evolution due to the differences in static pressure accounts for the three different curves.

Calculations were also carried out for $\mathrm{Mn}$. Because determined values of $\mathrm{Mn}$ content included not only metallic $\mathrm{Mn}$, but also $\mathrm{Mn}$ as $\mathrm{MnO}$ that failed to float up, these values were higher than the calculated values for metallic Mn. The values were lower, however, than the calculated amount of $\mathrm{Mn}+\mathrm{MnO}$.

The amount of evolved $\mathrm{CO}$ gas was not determined, but the acceptability of these calculated values will be discussed later with reference to the measured values reported by Ishihara et al.16)

\section{Intensity of Rimming Action}

The equations used in the former section also allow to calculate the intensity of rimming action, provided the teeming rate and the teeming composition are known. In this section the change of rimming action was examined as the solidification proceeds and also the dependence of rimming action on the composition of the melt was discussed.

Change of CO Evolution and Mn Deoxidation with the Progress of Solidification

According to the mechanism suggested by the present authors, the solidifying rate is rather big in the 


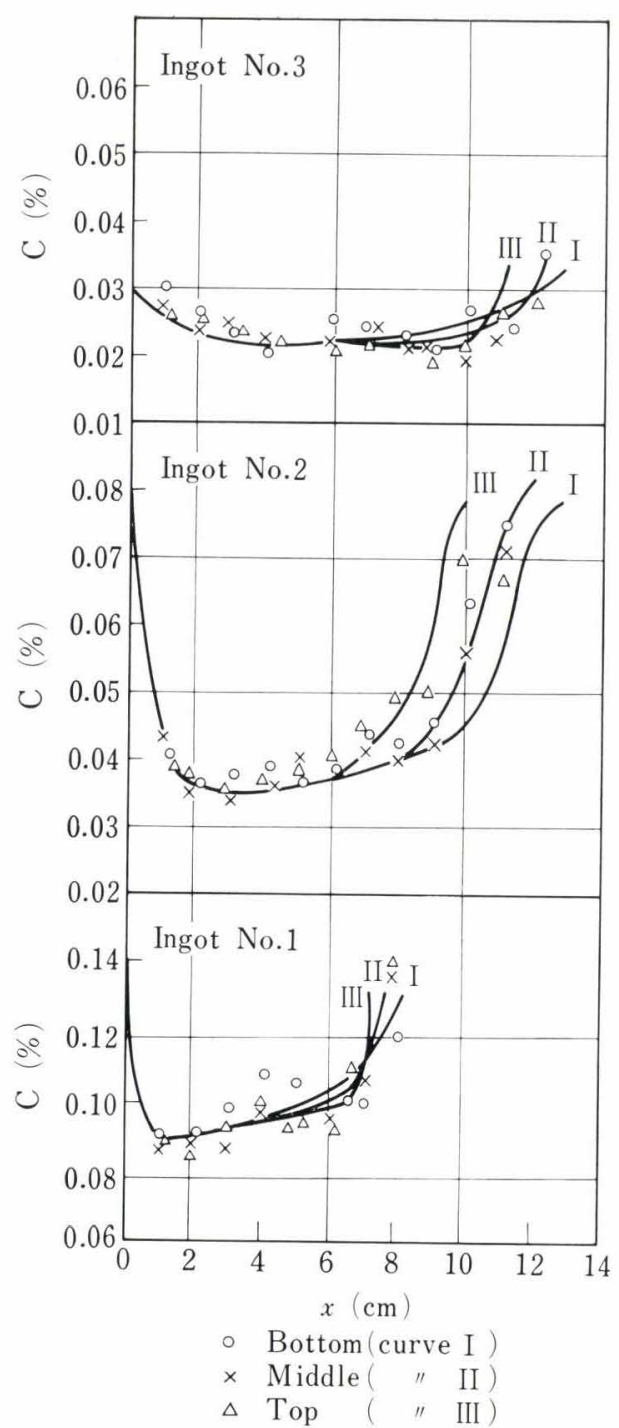

Fig. 6. Comparison between calculated and measured values of carbon concentration in rim layer

initial stage of solidification, so that the degree of supersaturation required for $\mathrm{CO}$ gas to evolve is quite high. Consequently the gas evolution is not favored, and when the solidification rate is infinite, $\mathrm{CO}$ gas does not evolve. On the contrary, if the solidification rate is lowered, the required degree of supersaturation is reduced eventually reaching unity. The amount of $\mathrm{CO}$ gas evolution, therefore, is a function of the distance from the surface of an ingot. Correspondingly deoxidation of $\mathrm{Mn}$ is affected.

In Fig. 7 (a), oxygen (\%) reacted to form $\mathrm{CO}$ gas $\left([\mathrm{O}]_{\mathrm{Co}}\right)$ and that consumed to react with $\mathrm{Mn}\left([\mathrm{O}]_{\mathrm{MnO}}\right)$ were plotted as the ordinate. In Fig. 7 (b), the oxygen consumed to form $\mathrm{CO}$ gas per unit time and unit solidification surface area was taken as the ordinate. The abscissa gives the solidified thickness in the both figures.

At the bottom section of an ingot, the amount of oxygen consumed as $\mathrm{CO}$ gas, $[\mathrm{O}]_{\mathrm{co}}$, increases as the solidification prodeeds, reaches a maximum and then decreases. The initial increase can be explained by the decrease in the required degree of supersaturation for $\mathrm{CO}$ gas evolution caused by the lowering of solidifying rate and the subsequent decrease is attributed to the in-

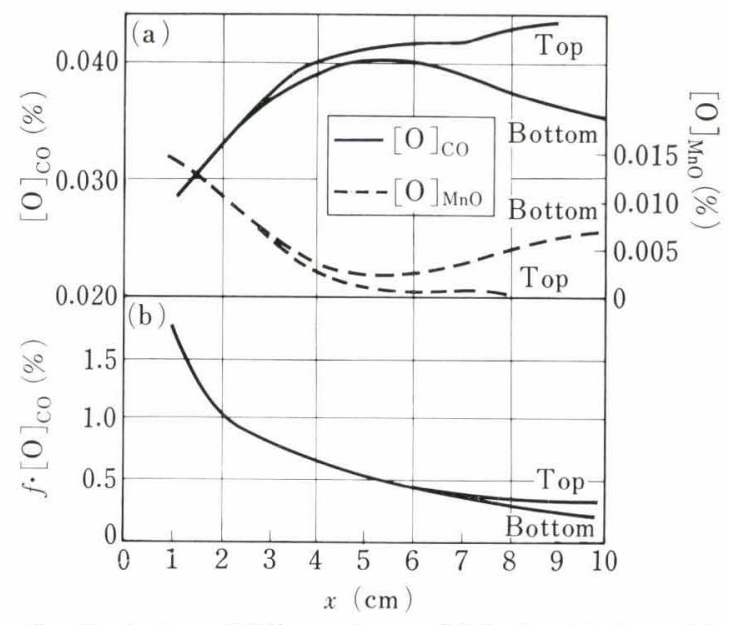

Fig. 7. Evolution of $\mathrm{CO}$ reaction and Mn deoxidation with progress of solidification

crease in the static pressure with the progress of solidification. For the top section, the increase in the static pressure discontinues at the end of casting, and this brings about another increase in the amount of produced CO gas.

The amount of $\mathrm{CO}$ gas produced per unit time gradually decreases as the solidifying rate decreases.

Effect of the Teeming Composition on Rimming Intensity

As already explained in the above section, the rimming intensity is affected not only by the teeming composition but also by the change of the solidifying rate and by the change of static pressure with progress of casting. However, only the teeming composition was taken as the variable for the following calculation assuming other two factors to be constant.

Although the solidification rate and the static pressure may be fixed to various values, they were taken as $0.0141 \mathrm{~cm} / \mathrm{sec}$ and $1.23 \mathrm{~atm}$, respectively, which correspond to the situation where the blowholes start to form. These two values are used, because the intensity of rimming action has the greatest influence on the formation of blowholes. On this basis, the effect of teeming composition on rimming action was calculated. The result is shown in Fig. 8 (a). Examination of this figure shows that the present result is in a reasonable agreement with that obtained by Matsuno et $a l^{7)}$ although slight difference in absolute values exists between these two results. Along the same line, Nilles ${ }^{6}$ ) also calculated the effect of the teeming composition on the rimming intensity, the result of which was quite different from the present one.

As evident from Fig. 8 (a), when the carbon content is raised at a constant oxygen concentration, $\mathrm{CO}$ evolution increases up to a certain carbon content and beyond this content it remains almost constant. In the former region, the increase in carbon content reduces $\mathrm{Mn}$ deoxidation and promotes $\mathrm{CO}$ formation. On the contrary, in the latter region deoxidation by Mn does not take place, and increase in $\mathrm{C}$ content contributes only to the reduction of the equilibrium oxygen concentration. The increase in $\mathrm{CO}$ evolution corresponding to this reduction of the equilibrium oxygen concentration is negligibly small. Fig. 8 (b) covers the transition region of the two. Each of these region 


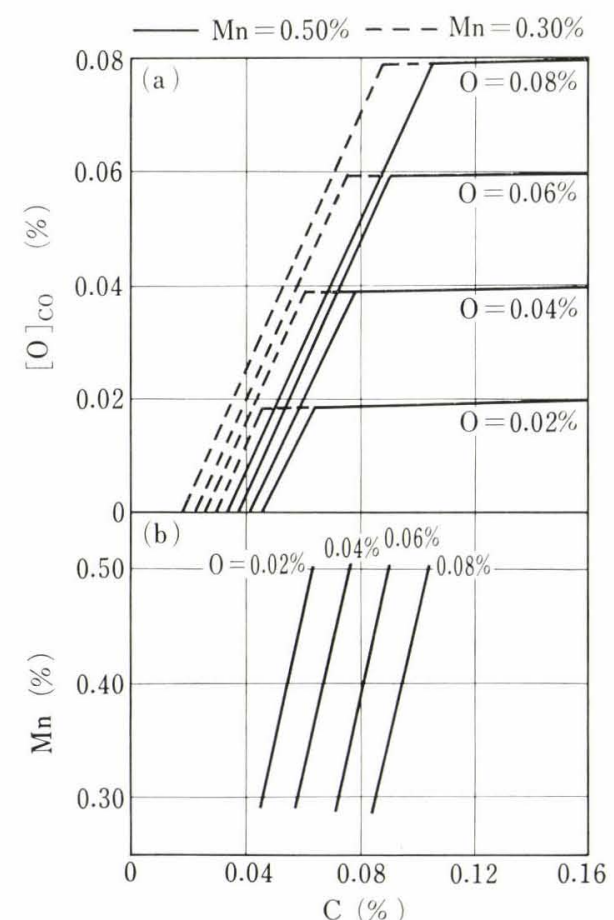

Fig. 8. Relation between rimming intensity and cast elements

has its own characteristics: in the first region the intensity of rimming action is not greatly influenced by the variation of the $\mathrm{O}$ content, whereas in the latter region the influence is strong. However, the effect of carbon content on the intensity of rimming action is just opposite to that of oxygen content. An optimum utilization of the characteristics of these regions will be very useful in realizing a stable rimming action.

So far, the concentration variations of $\mathrm{C}, \mathrm{Mn}$, and $\mathrm{O}$ were regarded to occur independently. In the actual process, however, contents of $\mathrm{O}$ and $\mathrm{C}$ in the ladle are mutually dependent. It is therefore necessary to have knowledge about $[\mathrm{C}]_{L}-[\mathrm{O}]_{L}$ relation in order to study the intensity of rimming action for steels having different carbon contents.

Using an equation,

$$
[\mathrm{O}]_{L}[\mathrm{C}]_{L}=0.015[\mathrm{C}]_{L}+0.00175^{6)}
$$

which, from the authors' experience, is a fairly good representation of carbon and oxygen content in the ladle, the intensity of rimming action was calculated. The result gave a maximum at a certain $\mathrm{C}$ content, as reported by many authors. ${ }^{16)-18}$ ) The carbon content corresponding to this maximum rimming action varies somewhat with $\mathrm{Mn}$ content. Some calculated values are given in the following table:

\begin{tabular}{l|lll}
\hline $\mathrm{Mn}(\%)$ & 0.30 & 0.40 & 0.50 \\
\hline $\mathrm{C} \quad(\%)$ & 0.06 & 0.07 & 0.08
\end{tabular}

Ishihara $^{16)}$ reported that the carbon content corresponding to the most active rimming action at $\mathrm{Mn}=$ $0.30 \%$ was around $\mathrm{C}=0.06 \%$, which agrees very well with the present result of calculation.

\section{A Consideration on Primary Blowhole}

The formation of primary blowhole has been studied by many authors, ${ }^{19)-23)}$ but so far, none of them seems to have tried to connect directly the formation of primary blowhole with the amount of $\mathrm{CO}$ gas evolution (the intensity of the rimming action). Instead, most of them employed some other factors which are related to the amount of $\mathrm{CO}$ gas evolution, for example the shape of the ingot top or the capping time. In this sense their approaches were indirect.

Asano et al. ${ }^{22}$ demonstrated in their recent report that the location of primary blowhole formation in semi-killed steel could be explained by the growth rate of gaseous bubble and the solidifying rate. The present authors investigated the dependence of the primary blowhole formation on the amount of $\mathrm{CO}$ formation and the rate of solidification, basing on their own model and refering to the idea of Asano et al. As a result, it was found that the location of primary blowhole formation may be explained by the following interpretation.

The formation of CO gas in mole per unit time (sec) and unit area of solid-liquid interface is

$$
\rho_{\mathrm{Fe}} f[\mathrm{O}]_{\mathrm{Co}} \times \frac{1}{16} \times \frac{1}{100}
$$

The volume of $\mathrm{CO}$ gas formed per unit time and unit area of solid-liquid interface at a static pressure $P$ (atm) and at $1530^{\circ} \mathrm{C}$ is

$$
\begin{aligned}
V & =\{22400 /(16 \times 100)\}(1+1530 / 273) \rho_{\mathrm{Fe}}[\mathrm{O}]_{\mathrm{Co}} \cdot f / P \\
& =K f[\mathrm{O}]_{\mathrm{co}} / P\left(\mathrm{~cm}^{3} / \mathrm{sec}\right)
\end{aligned}
$$

Since the growth rate of gaseous bubbles is proportional to the volume, the rate may be expressed as in the following equation:

$$
R=m K f[\mathrm{O}]_{\mathrm{co}} / P(\mathrm{~cm} / \mathrm{sec})
$$

where $m$ is the ratio of solidifying area to the area where $\mathrm{CO}$ bubbles form; $m$ is greater than unity. Assuming that bubbles float up to the surface when the growth rate $R$ of bubbles is greater than the solidifying rate by $\alpha$,

$$
(R-f) \geqq \alpha
$$

then Eq. (16) may be rewritten as,

$$
[\mathrm{O}]_{\mathrm{CO}} / P \geqq 1 / m K+\alpha /(m K \cdot f)
$$

Since the solidified thickness $x$ is related with the rate of solidification, $f$, by $f=A^{2} / 2 x$, Eq. (16) becomes:

$$
[\mathrm{O}]_{\mathrm{Co}} / P \geqq 1 / m K+\left(2 \alpha / A^{2} m K\right) x
$$

In the present case, the location of primary blowhole formation is equal to 2 to $5 \mathrm{~cm}$ and the corresponding range of $[\mathrm{O}]_{\mathrm{co}} / P$ is 1.5 to $4.0 \times 10^{-2}$. Eq. (17) can therefore be represented approximately by:

$$
[\mathrm{O}]_{\mathrm{co}} / P \geqq\left(2 \alpha / A^{2} m K\right) x \ldots
$$

Values of $[\mathrm{O}]_{\mathrm{co}} / P$ at the bottom of ingots calculated for test ingots Nos. 1, 2, 3, and 4, respectively, are shown in Fig. 9 as a function of distance $x$. The constant $\left(2 \alpha / A^{2} m K\right)$ in Eq. (18) is estimated to be $8 \times 10^{-3}$ $(1 / \mathrm{atm} \cdot \mathrm{cm})$, so that the dotted line in the figure gives the region of primary blowholes formation. In the 


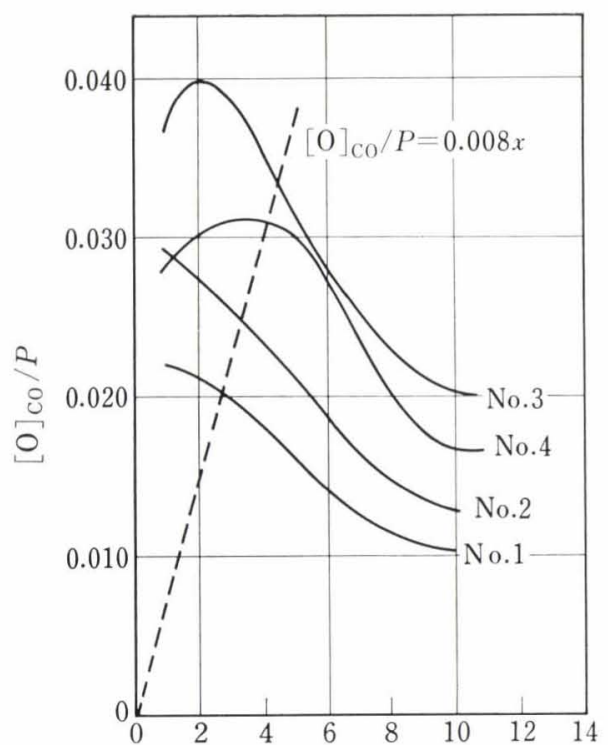

Thickness of rim layer, $x(\mathrm{~cm})$

Fig. 9. Starting position of primary blowhole formation

region where $[\mathrm{O}]_{\mathrm{co}} / P$ is higher than this line, bubbles are separated to float up and no primary blowhole is formed. In the region where $[\mathrm{O}]_{\mathrm{co}} / P$ is lower than this line, a portion of the bubbles are caught and remain to form primary blowholes.

Accordingly, the intersection of the dotted line and the curves is the starting position of primary blowhole formation. Comparison of these points calculated for the test ingots with the actually observed solid skin thickness is shown in Table 2, which shows a good agreement between observed and calculated values.

Table 2. Comparison between observed values of solid skin and calculated values

\begin{tabular}{c|cc}
\multirow{2}{*}{$\begin{array}{c}\text { Ingot } \\
\text { No. }\end{array}$} & \multicolumn{2}{|c}{ Solid-skin thickness $(\mathrm{mm})$} \\
\cline { 2 - 3 } & Calculated & Observed \\
\hline 1 & 26 & 29 \\
2 & 32 & 32 \\
3 & 43 & 44 \\
4 & 40 & 43 \\
\hline
\end{tabular}

Furthermore, it was found that each primary blowhole in the test ingots grew from the end of the solid skin to the end of the rim layer, and that the growth was terminated at the time of capping. Hence, the length of a primary blowhole is related to the thicknesses of the two layers, i.e. the solid skin and the rim layer. Since the thickness of the rim layer can be calculated from the capping time, the length of primary blowhole can also be determined by calculation. The calculated lengths were plotted against the observed values in Fig. 10, which show a good agreement.

The amount of primary blowholes formed strongly depends on the intensity of rimming action. The authors measured the ratio of the area occupied by primary blowholes to the total cross-sectional area of a plane normal to the growing direction of blowholes. The area ratio thus determined was plotted against

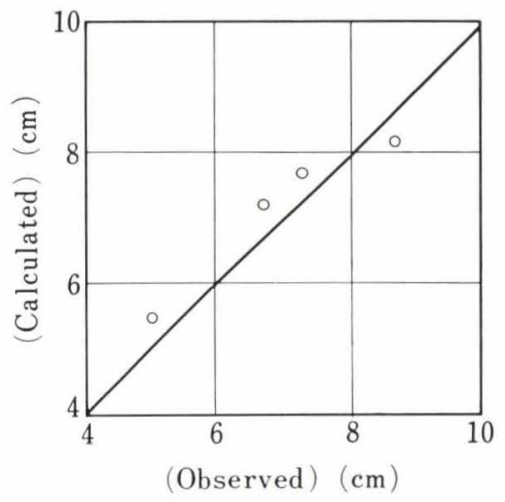

Fig. 10. Comparison of calculated and measured length of primary blowhole

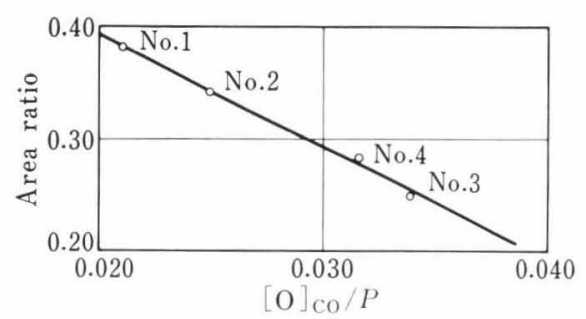

Fig. 11. Relation between primary blowhole density and $[\mathrm{O}]_{\mathrm{CO}} / P$

$[\mathrm{O}]_{\mathrm{co}} / P$ under which primary blowhole start to form (Fig. 11). It can be stated from this figure that, when the intersection in Fig. 9 takes place at high value of $[\mathrm{O}]_{\mathrm{co}} / P$, bubbles are caught but only in a very small amount.

Thus, if the teeming conditions and the teeming composition are known, the length of primary blowhole, the thickness of the solid skin and the density of primary blowhole can be calculated.

\section{Conclusions}

Equations were obtained to express the amount of $\mathrm{CO}$ gas evolution (rimming intensity), the degree of deoxidation by $\mathrm{Mn}$ and the concentration of each solute element in the rim layer in terms of the teeming composition and the teeming conditions, based on the experimental results on 14-t bottom-poured rimming steel ingots. Various reactions were taken into account. The phenomena involved in the solidification of rimmed steel is so complicated that many assumptions are necessary to obtain the relatively simple equations. Moreover, precision of chemical and physical constants required for numerical calculations are not satisfactory. Consequently, the obtained equations would need modifications to be applied to cases where solidification proceeds under much different conditions. Nevertheless, the equations are good enough to give reasonable accuracy as far as the ordinary conditions are concerned.

Using these equations, the intensity of rimming action was successfully calculated for various teeming compositions, and it is possible to estimate suitable conditions to achieve stable rimming action. The equations were also able to explain the maximum rimming action of rimming steels at a certain concentration of carbon. The concentration of carbon predicted 
by the equations was in a good agreement with the observed value.

It was demonstrated, through the examination of primary blowhole formation in the test ingots, that the length of primary blowhole, the thickness of solid skin and the amount of primary blowholes formed could be calculated from the teeming conditions and the teeming composition. However, since there exists complicated influence of various factors, e.g. the washing effect by the floatation of gas bubbles, further examination would be necessary to apply the procedure to the cases where conditions are much different (different pouring method, e.g. top pouring, much different concentrations of $\mathrm{C}, \mathrm{Mn}, \mathrm{O}$, or different shape and dimension of the ingot) from those of present study.

\section{Acknowledgements}

The authors wish to thank Dr. Kōki Gunji, Chief of Steelmaking Laboratory, National Research Institute for Metals, for a lot of helpful discussion and suggestions during this work.

\section{REFERENCES}

1) A. Hultgren and G. Phragmen: Trans. Met. Soc. AIME, 135 (1939), 133.

2) A. Hayes and J. Chipman: Trans. Met. Soc. AIME, 135 (1939), 85.

3) S. Ishihara: Tetsu-to-Hagané, 40 (1954), 403.

4) S. Ishihara: Tetsu-to-Hagané, 40 (1954), 487.

5) E. Schurman, P. Hadjisaroso, and O. Peter: Stahl u. Eisen, 85 (1965), 61.

6) P. Nilles: J. Iron Steel Inst., (1964), 601.
7) J. Matsuno and S. Okano: Tetsu-to-Hagané, 52 (1966), 1522.

8) J.A. Burton, R. C. Prim, and W. P. Slichter: J. Chem. Phys,, 21 (1953), 1987.

9) Thermochemistry for Steelmaking (II), (1962), 702, AIME.

10) Y. Kawai: Tetsu-to-Hagané, 42 (1956), 514.

11) W. A. Fischer and H. O. Leichner: Arch. Eisenhüttenze., 35 (1964), 586.

12) W. A. Fischer, H. Spitzer, and M. Hishinuma: Arch. Eisenhüttenw., 31 (1960), 365.

13) T. Saito and K. Maruya: Senken Tech. Report, 12 (1956), 27.

14) Japan Society for the Promotion of Science: The 19th Committee, Rept., No. 7942, (1965).

15) Japan Society for the Promotion of Science: The 19th Committee, Rept., No. 6372, (1961).

16) S. Ishihara: Seitetsu Kenkyu, 201 (1952), 38.

17) K. Kato: Seitetsu Kenkyu, 201 (1952), 89.

18) H. Kosmider, H. Neuhaus, H. Kirschning, and W. Münstermann: Stahl u. Eisen, 77 (1957), 133.

19) M. Ward: J. Iron Steel Inst., (1965), 486.

20) Y. Itoh, A. Hoshino, and H. Itoh: Tetsu-to-Hagané, 52 (1966), 463.

21) S. J. Smith: J. Iron Steel Inst., (1953), 16.

22) K. Asano and T. Ōhashi: Tetsu-to-Hagané, 51 (1965), 1874.

23) The Joint Research Society of ISIJ, 34th Steelmaking Division, No. 901, (1966).

24) K. Kato: Seitetsu Kenkyu, 200 (1952), 127.

25) F. B. Pickering: Steel Times, 13 (1964), 11.

26) W. A. Fischer and H.J. Fleischer: Arch. Eisenhüttenw., 32 (1961), 1 .

27) L. von Bogdandy: Arch. Eisenhüttenze, 32 (1961), 275. 